Public Abstract

First Name:David

Middle Name:Howard

Last Name:Morris

Adviser's First Name:Denis

Adviser's Last Name:McCarthy

Co-Adviser's First Name:

Co-Adviser's Last Name:

Graduation Term:SS 2016

Department:Psychology

Degree:PhD

\title{
Title:A MULTI-METHOD ANALYSIS OF THE ACQUIRED PREPAREDNESS MODEL FOR RISK OF ALCOHOL PROBLEMS
}

The acquired preparedness model (APM) integrates both general risk factors and alcohol-specific factors to understand the development of alcohol use and its associated problems. The present project utilized an innovative multi-method approach (self-report and neurophysiological techniques) to conduct a more comprehensive and in-depth analysis of the APM. Participants were 137 young adult ( $\mathrm{M}=22$ years old, SD $=3,59 \%$ female) social drinkers recruited from a Midwest college town. Self-report measures assessed participants' sensitivity to reward (general risk factor) and the outcomes they expect to happen after drinking (alcohol-specific factor). Neural responses were recorded while participants responded to infrequent, neutral targets (general risk factor) and while they viewed infrequent, pictures of alcoholic beverages (alcohol-specific factor). Consistent with the APM, results using self-report measures indicated that individuals more sensitivity to reward have more positive expectancies about the outcomes of drinking, which are associated with more frequent drinking. However, results also suggest that common measurement method contributed to a large proportion of the observed associations, particularly those including neurophysiological variables. Further research is necessary to determine the extent to which common measurement method accounts for the APM. Additional research is also necessary to clarify how neural responses to neutral targets and pictures of alcoholic beverage pictures relate to one another. 